\title{
ALUNOS DO ENSINO MÉDIO NOTURNO E SUAS EXPECTATIVAS COM ESSA MODALIDADE DE ENSINO
}

\author{
Marcelo Marques Carneiro* \\ Sebastião Silva Costa**
}

\section{RESUMO}

O presente trabalho tem por objetivo investigar as expectativas dos alunos do Ensino Médio regular que estudam no turno noturno. A metodologia utilizada foi a quali-quantitativa, tendo como instrumento de coleta de dados o questionário e a entrevista estruturada. A pesquisa foi realizada em uma escola estadual do município de Tanque Novo/BA, no ano letivo de 2018, com uma amostra composta por dez estudantes do ensino médio regular noturno, matriculados no $2^{\circ}$ ano do referido nível de ensino. A amostra foi dividida em dois grupos: G1, com alunos de menor rendimento, e G2 com os de maior rendimento escolar. Foi feita a apresentação dos gráficos e discussão dos dados colhidos na pesquisa. Os resultados indicam que a maioria almeja, além da certificação, a preparação para a inserção no mercado profissional, bem como de um ensino superior de qualidade, o que pressupõe a necessidade de um trabalho diferenciado voltado para melhor atendimento dos alunos do turno noturno.

Palavras-chave: Ensino Médio. Expectativas. Preparação.

*Mestrando em Ciências da Educação pela Facultad Interamericana de Ciencias Sociales. Assunção - Paraguai. Contatos: E-mail: marcelomarquestn@gmail.com (77) 99902-9161.

** Mestrando em Ciências da Educação pela Facultad Interamericana de Ciencias Sociales. Assunção -

Paraguai. Contatos: E-mail: tiaocosta@bol.com.br (77) 99988-4404. 


\section{INTRODUÇÃO}

Quando se trata de Ensino Médio é normal que venham interrogações, principalmente sobre as expectativas de quem frequenta este nível de ensino, e este texto tem como objetivo investigar as expectativas dos alunos do Ensino Médio noturno em relação à sua vida acadêmica.

Para chegar ao objetivo do trabalho foram planejados objetivos específicos com a função de dar maior sustentação e norte a pesquisa, esses objetivos passam por: verificar se a condição socioeconômica do estudante interfere na busca por qualificação para os estudos; descobrir os anseios dos alunos em relação ao ensino médio regular; e verificar se as avaliações interferem na motivação em relação aos estudos.

É notável que os governantes sempre apresentem um discurso e algumas ações para que os jovens frequentem a escola, dentre as quais pode-se citar o programa Bolsa Família do governo federal.

O programa Bolsa Família segundo o Ministério do Desenvolvimento Social (MDS) tem por objetivo estimular o acesso à educação, a permanência do aluno na escola e de ajudar a família a romper com a barreira da pobreza.

Esses programas de incentivo à educação dos jovens, juntamente com a grande cobrança do mercado de trabalho por mão de obra melhor qualificada faz com que o Ensino Médio caia sempre em debate, em especial quanto ao seu aspecto estrutural, no qual se busca colocar novos rumos com este nível de estudo.

As discussões sobre as novas propostas do ensino médio são importantes e pertinentes, pois, para que o Ensino Médio se apresente como uma etapa final da Educação Básica e de preparação para o mercado de trabalho atrativo ao aluno é preciso saber quais são os reais motivos que os fazem ingressar neste nível de ensino.

A palavra expectativa vem do latim expectare, e que de acordo com o dicionário escolar da língua portuguesa é um substantivo feminino que representa possibilidade; probabilidade; esperança fundada em promessa; aquilo que se espera e também expectação. 
Para que a expectativa possa existir também é necessária a previsão, informação ou condição que sirva de base para suas ascensões, caso isso não ocorra o sentimento de expectativa passa a ser uma utopia.

A expectativa dos alunos do ensino médio tem sua base sustentadora no fato destes estarem cursando este nível de ensino, onde eles podem depositar seus anseios e sonhar com uma melhor formação acadêmica e/ou profissional.

\section{NEOLIBERALISMO E EDUCAÇÃO}

Para Bianchetti (2005) nos anos 90, o projeto neoliberal de educação executou com relativo sucesso o alargamento do ensino fundamental, e dessa maneira a articulação do sistema educativo com o sistema produtivo deve ser necessária.

De acordo com autor o sistema educativo deve responder de maneira direta à necessidade do sistema produtivo, e assim o neoliberalismo, ao não aceitar a igualdade social, deixa livre às leis da oferta e da demanda o que faz da escola formadora de recursos humanos para a estrutura de produção. Assim o mecanismo do mercado se torna auto regulador, equilibrando as demandas surgidas do setor produtivo com a oferta vinda das instituições educativas.

Ainda de acordo com Bianchetti (2005), essa lógica coloca a educação como um bem econômico que deve responder, da mesma maneira que uma mercadoria, à lei da oferta e da demanda.

Assim, pensa-se as escolas públicas, reduzidas ao mínimo, frente à necessidade de atrair a população estudantil que as justificasse, sendo obrigadas a incorporar-se às leis do mercado, competindo com as outras escolas públicas e com as privadas, e sua existência seria uma resultante da qualidade do serviço oferecido, e não somente do fato de pertencer a uma estrutura estatal.

Em síntese o neoliberalismo

defende uma escola que se constitua em efetivo instrumento de controle social e se paute por qualidade e produtividade, características essas definidas com base no resultado educacional obtido e estabelecidas por meio de padrões, indicadores e medidas. Daí a preocupação tanto com a proposição de um currículo nacional, ou, segundo o eufemismo preferido entre nós, de Parâmetros 
Curriculares Nacionais (PCN), como com a criação de um sistema de avaliação do desempenho das escolas. Ambos são vistos como essenciais para o alcance de qualidade em educação. (MOREIRA, 1997, p. 94)

É inegável a expansão de oportunidades escolares no ensino fundamental regular como é incontestável o aumento do grau de escolarização pela necessidade de melhor colocação no mercado de trabalho.

Sendo a década de 90 marcada pela tentativa de reformas educacionais que buscassem, sobretudo, estender a educação, conforme a expressão de Freire (2001) "uma educação para todos", erradicando graves problemas de exclusão e fracasso escolar.

Entretanto a política educacional neoliberal teve um caráter antipopular por estar voltada à formação técnica e ético-política da classe trabalhadora de acordo com a cultura empresarial.

\section{O ENSINO MÉDIO}

O ensino médio existente hoje teve seu início em 1988, nesse momento ele passa a abraçar toda população, seja ela de elite ou não.

\footnotetext{
O conceito de ensino médio foi criado a partir da Lei de Diretrizes e Bases da Educação (LDB), de 1996, em substituição ao antigo Segundo Grau. A educação profissional de nível técnico, por sua vez, passou a ter organização curricular independente do Ensino Médio. De acordo com a LDB, o ensino médio conta com um currículo de base nacional comum, voltada para 0 desenvolvimento de competências e habilidades básicas. (MENEZES, 2001, p. 01)
}

Sendo o último bloco da educação básica no Brasil, ele dura em média três anos e é pré-requisito básico para o acesso ao ensino superior. E pretende-se nesta etapa de ensino da uma formação visando o mercado de trabalho, além de aperfeiçoar os conhecimentos do indivíduo já apanhados nas anteriores e como ser humano dotado de razão.

Este nível de ensino, sendo de responsabilidade dos Estados, e se configurando como a etapa final da educação básica, de acordo com a Lei de Diretrizes e Bases da Educação Nacional (LDBEN) não é obrigatório. Porém os 
Estados de acordo o estabelecido no Plano Nacional de Educação (PNE) têm a função de gradativamente, fazer o ensino médio uma etapa obrigatória, disponibilizando mais vagas para que todos que concluírem o ensino fundamental possam ser atendidos.

Hoje se vive um momento onde o ensino médio está sob discussão, visando a implantação do que é chamado de Novo Ensino Médio, que de forma resumida trás maior autonomia ao estudante de focar em uma área de estudo que lhe interesse mais.

Com base na análise das propostas que o Novo Ensino Médio propõe, de flexibilização da grade curricular, o estudante optará por uma área do conhecimento que ele quer aprofundar seus estudos, e essa nova proposta apresenta também uma Base Nacional Comum Curricular (BNCC), sendo obrigatória em todas as escolas da educação infantil ao ensino médio.

As competências e conhecimentos essenciais ficam a cargo da BNCC, e deverão ser oferecidos a todos os alunos na parte comum, com 1.800 horas, envolvendo todas as áreas do conhecimento (Linguagens; Ciências Humanas e Ciências da Natureza e Matemática) e todos os componentes curriculares do ensino médio definidos pela LDBEN e nas diretrizes curriculares nacionais de educação básica.

Apesar dessa autonomia o Novo Ensino Médio mantém algumas disciplinas obrigatórias (Português e Matemática) durante o curso, juntamente com a parte diversificada para o aluno poder se dedicar e já buscar um aperfeiçoamento para o mercado de trabalho ou já visando um curso superior.

Além de preparar o estudante para o mercado de trabalho e aperfeiçoar os conhecimentos já adquiridos, o ensino médio também tem a possibilidade de ser ofertado paralelamente com a formação para o exercício de profissões técnicas, desde que a modalidade obedeça à formação e o objetivo geral desta etapa.

Existem três possibilidades de se articular o ensino médio e a formação técnica profissionalizante, uma dessas formas é a Integrada, que é realizada na mesma unidade escolar que o estudante cursa o ensino médio, sendo necessária apenas uma única matrícula. 
Outra forma é a concomitante, que tem a possibilidade de ser ministrada na mesma escola em que 0 aluno estuda o ensino médio, também existe a possibilidade de ser ministrada em outra instituição de ensino, sendo facultativo o convênio entre as diferentes escolas. $E$ também o subsequente, que é oferecido aos alunos que já concluíram o ensino médio.

O estudante que se dispõe a fazer a articulação entre ensino médio e o ensino técnico profissionalizante deve tratar os dois cursos com a mesma seriedade, pois, o diploma de técnico de nível médio só será emitido ao estudante que concluir, também, o ensino médio.

O currículo do ensino médio é pautado pelos Parâmetros Curriculares Nacionais para o Ensino Médio (PCNEM), onde as orientações publicadas para este nível de ensino é formada por três volumes sucessivos de cada área, sendo elas: Linguagem, Código e suas Tecnologias, Ciências da Natureza, Matemática e suas Tecnologias e Ciências Humanas e suas Tecnologias.

Hoje essas áreas do conhecimento são ensinadas em concordância com o que propõe o Exame Nacional do Ensino Médio (ENEM), que atualmente é um dos principais caminhos de ingresso ao ensino superior.

\section{O ENSINO MÉDIO NOTURNO}

Boa parte das discussões sobre democratização da educação tem incluído a temática do ensino médio regular noturno, sobretudo pela deterioração que vem sofrendo os cursos ministrados nesse período, registrando altos índices de evasão e repetência, isso que o MEC/INEP afirma, registrando 12,9 \% de evasão dos alunos matriculados na primeira série do ensino médio entre os anos de 2014 e 2015.

Um dos problemas do curso noturno e que historicamente tem se tornado uma de suas características é o de um curso altamente seletivo, constituído, na sua maioria, por alunos que vem da classe baixa e que necessitam trabalhar. Esse fato é justificado pela necessidade de contribuir com o orçamento doméstico e é revelador do seu baixo nível socioeconômico, e segundo o Censo de 2013 um percentual de $40 \%$ de alunos do noturno não trabalhava. 
Essa característica-problema indica a manifestação do indisfarçável papel desempenhado pela escola na seleção social de classes. Além dos fatores já mencionados, destaca-se, também, a alta média de idade dos alunos do curso noturno, onde em 2013 o MEC registrou 50\% dos discentes do noturno com idade entre 18 e 21 anos, ao passo que no diurno a maioria (54,7\%) tem menos de 17 anos.

Este fato denota não só um possível ingresso tardio no sistema de ensino, mas, sobretudo, uma história quase certa de não promoção em outros anos letivos.

A existência do aluno e do trabalhador-estudante, do aluno que percorre a trajetória de escolarização sem interrupções e daquele que retorna à escola após um período de abandono, sugerem a possibilidade de oferta diversificada de ensino, no sentido de criar ambientes escolares capazes de acolher os diferentes públicos que vêm demandando o Ensino Médio Noturno e potencializar suas escolhas futuras. (BRASIL, 2006, p.99)

Desta maneira, cabe ao professor ter consciência que a quantidade de informações passadas aos alunos não é fator principal na educação, sendo de fundamental importância capacitá-los para lidar com tais informações, fazendo com que cada aluno se aproprie delas, e, principalmente, as produzam ou as reconstruam, a partir de suas próprias perspectivas.

A lei de Diretrizes e bases da Educação de 1996 define que a Educação Básica tem por finalidade "desenvolver o educando, e assegurar-lhe a formação indispensável para o exercício da cidadania e fornecer-Ihe meios para progredir no trabalho e em estudos posteriores".

De acordo com Caporaline (1991), apesar de cumprir uma função fundamental de assegurar o direito à educação desses jovens que de alguma maneira não podem estudar no diurno, o ensino noturno consolida-se, de modo geral, como um ensino de pouca qualidade.

Se é certo que o professor do noturno se defronta com inúmeros fatores de ordem socioeconômica, administrativa e/ou metodológica, cuja influência negativa é dificilmente reduzida, não seria mais honesto se analisassem tais fatores com o aluno trabalhador, ao invés de deixá-lo muitas vezes erroneamente convicto de que é ele, exclusivamente ele, a causa principal do seu fracasso? Por que não 'nosso fracasso'? É preciso acentuar que ninguém está sozinho como responsável por uma condição frustrante em termos de 
realização escolar no noturno. O professor pode ficar limitado por um conjunto de circunstâncias que escapam as suas decisões e interferências. No entanto, é verdade, precisa lutar para romper essa condição. (CAPORALINI, 1991, p. 186)

Dessa maneira entende-se que a escola procura se eximir da culpa do fracasso do aluno, que em sua maioria já vem para a escola sem se alimentar adequadamente e extenuada pelo trabalho e pelo tempo curto de repouso da noite anterior. A escola deve reconhecer suas próprias dificuldades, buscar alternativas para mudanças, repensar a sua estrutura, sua organização e a sua proposta.

Oliveira (2005) cita o fato de que o sistema de ensino, apesar de abrigar um público tão diferenciado e com problemas tão específicos, não tem sido capaz de produzir medidas significativas no sentido de conhecer melhor e atender os interesses e necessidades dos alunos que estudam à noite.

Segundo Bianchetti (2005), o papel da escola pública e dos educadores é o de integrar tanto a formação humana quanto para o preparo ao trabalho, não sendo este último um fim em si mesmo.

\section{O PROFESSOR DO ENSINO MÉDIO}

Em uma escola que busca a formação humana integral dos estudantes é imprescindível que a equipe de professores identifique as expectativas e necessidades de desenvolvimento integral dos estudantes nos aspectos físico, intelectual, emocional, social, cultural etc., articulando oportunidades educativas capazes de atendê-las, para isso o professor precisa de todo o apoio e de uma boa estrutura física e de pessoal da escola.

As políticas públicas e, mais especificamente as políticas educacionais, nesse cenário segundo a SEC/BA (2015) assumem também um papel de grande importância na medida em que definem, a partir dos interesses em jogo na sociedade, os direcionamentos mais amplos para enfrentar os desafios vividos no âmbito dos sistemas de ensino e do cotidiano das escolas.

Um exemplo importante das políticas públicas para a Educação Básica, fruto das lutas históricas dos professores, foi a aprovação da Resolução ํㅜ 2, de $1^{\circ}$ de julho de 2015, que estabelece as Diretrizes Curriculares Nacionais para a Formação 
Inicial e Continuada dos Profissionais do Magistério da Educação Básica. O capítulo VII, art. 18, da Resolução citada, ao tratar dos "profissionais do magistério e sua valorização", afirma que:

$\S$ 3 A valorização do magistério e dos demais profissionais da educação deve ser entendida como uma dimensão constitutiva e constituinte de sua formação inicial e continuada, incluindo, entre outros, a garantia de construção, definição coletiva e aprovação de planos de carreira e salário, com condições que assegurem jornada de trabalho com dedicação exclusiva ou tempo integral a ser cumprida em um único estabelecimento de ensino e destinação de $1 / 3$ (um terço) da carga horária de trabalho a outras atividades pedagógicas inerentes ao exercício do magistério [...]

Isto posto, fica esclarecido que valorizar e capacitar continuamente o professor, em especial o que atua no Ensino Médio, bem como investir em melhorias físicas nas instituições de ensino, é determinante para uma evolução e consequente melhora nos níveis de educação (ensino e aprendizagem) dos jovens que frequentam a escola pública.

\section{POLÍTICAS EDUCACIONAIS PARA O ENSINO MÉDIO}

De acordo com o documento "Planejando a Próxima Década: Conhecendo as 20 Metas do Plano Nacional de Educação", criado pelo MEC, por meio da Secretaria de Articulação com os Sistemas de Ensino, a elaboração do PNE implica

[...] assumir compromissos com o esforço contínuo de eliminação de desigualdades que são históricas no País. Portanto, as metas são orientações para enfrentaras barreiras para 0 acesso e a permanência; as desigualdades educacionais em cada território com foco nas especificidades de sua população; a formação para o trabalho, identificando as potencialidades das dinâmicas locais; e o exercício da cidadania. A elaboração de um plano de educação não pode prescindir de incorporar os princípios do respeito aos direitos humanos, à sustentabilidade socioambiental, à valorização da diversidade e da inclusão e à valorização dos profissionais que atuam na educação de milhares de pessoas todos os dias. (BRASIL, 2014, p.9)

No que diz respeito às metas definidas para o Ensino Médio destaca-se a Meta 3, que visava universalizar, até 2016, o atendimento escolar para toda a 
população de 15 a 17 anos e elevar, até o final do período de vigência do PNE, a taxa líquida de matrículas no ensino médio para 85\%.

A Meta 3 do PNE trata de um dos mais antigos problemas do atendimento educacional no Brasil, que é a universalização do Ensino Médio.

Para dar conta da meta proposta e melhorar a qualidade do Ensino Médio, o PNE aponta um conjunto de estratégias, dentre as quais se destaca a seguinte:

3.1. Institucionalizar programa nacional de renovação do Ensino Médio, a fim de incentivar práticas pedagógicas com abordagens interdisciplinares estruturadas pela relação entre teoria e prática, por meio de currículos escolares que organizem, de maneira flexível e diversificada, conteúdos obrigatórios e eletivos articulados em dimensões como ciência, trabalho, linguagens, tecnologia, cultura e esporte, garantindo-se a aquisição de equipamentos e laboratórios, a produção de material didático específico, a formação continuada de professores e a articulação com instituições acadêmicas, esportivas e culturais. (BRASIL, 2014, p.22)

Ainda com relação às políticas voltadas à melhoria da qualidade da educação brasileira, que atinge diretamente o Ensino Médio, destaca-se o debate em torno da elaboração da Base Nacional Comum Curricular (BNCC).

A proposta da BNCC se articula à meta do PNE ao se constituir como estratégia para fomentar a qualidade da Educação Básica, do fluxo escolar e da aprendizagem.

Para avançar nessa discussão o Ministério da Educação (MEC) convocou pesquisadores e professores representantes de todas as etapas da Educação Básica e representantes de secretarias da Educação dos estados e municípios, com a intenção de produzir uma versão do documento para ser amplamente discutida com os professores das diversas redes de ensino e demais agentes educativos de todo o território nacional com um olhar voltado a garantia dos direitos a aprendizagem dos alunos brasileiros.

Ainda de acordo com o MEC, após feita a consulta pública, esse documento deve tornar-se uma referência para a definição dos currículos nos sistemas de ensino e nas escolas brasileiras.

No contexto desse debate e na direção proposta pelo PNE (2014-2024), que busca responder ao objetivo de promover o direito à educação integral dos discentes, é que o governo da Bahia, por meio da Secretaria da Educação (SEC), 
vem assumindo o compromisso de desenvolver ações em todas as etapas e modalidades educacionais, consolidando sua política de fortalecimento da Educação Básica de modo a garantir uma educação de qualidade.

É preciso reconhecer que o momento da educação é importante, e a mobilização dos setores públicos e dos agentes educativos sociais favorecem o surgimento de possibilidades para a realização de um trabalho de alinhamento de esforços para melhorar a educação na Bahia e no Brasil.

\section{DADOS E DISCUSSÃO}

A pesquisa foi realizada no ano de 2018 com 10 (dez) estudantes do ensino médio regular noturno, matriculados no $2^{\circ}$ ano do referido nível de ensino, de uma escola estadual do município de Tanque Novo/BA. A amostra foi dividida em dois grupos (G1 e G2) com cinco (5) estudantes cada, onde o grupo G1 se caracteriza por ter alunos de menor rendimento, e o grupo G2 com alunos de maior rendimento escolar. Sendo utilizado o método qualiquantitativo, e, para a coleta de dados fez uso de questionário e entrevista estruturada.

Os dados da pesquisa mostram que o desejo de ter um nível superior após concluir o ensino médio é apontado como meta por $90 \%$ dos pesquisados, este número expressivo mostra que um ensino diferenciado no noturno é pertinente, pois neste turno percebe-se também que $90 \%$ dos pesquisados trabalham.

Apesar da vontade de ingressar em uma faculdade ser uma meta desses estudantes, o motivo principal para com o Ensino Médio é aprender mais, citado por $50 \%$ dos entrevistados, consequentemente esse "aprender mais" com o ensino médio, faz esses alunos pensarem também em arrumar um emprego melhor.

\section{Gráfico 1: Motivo para ingressar no Ensino Médio}

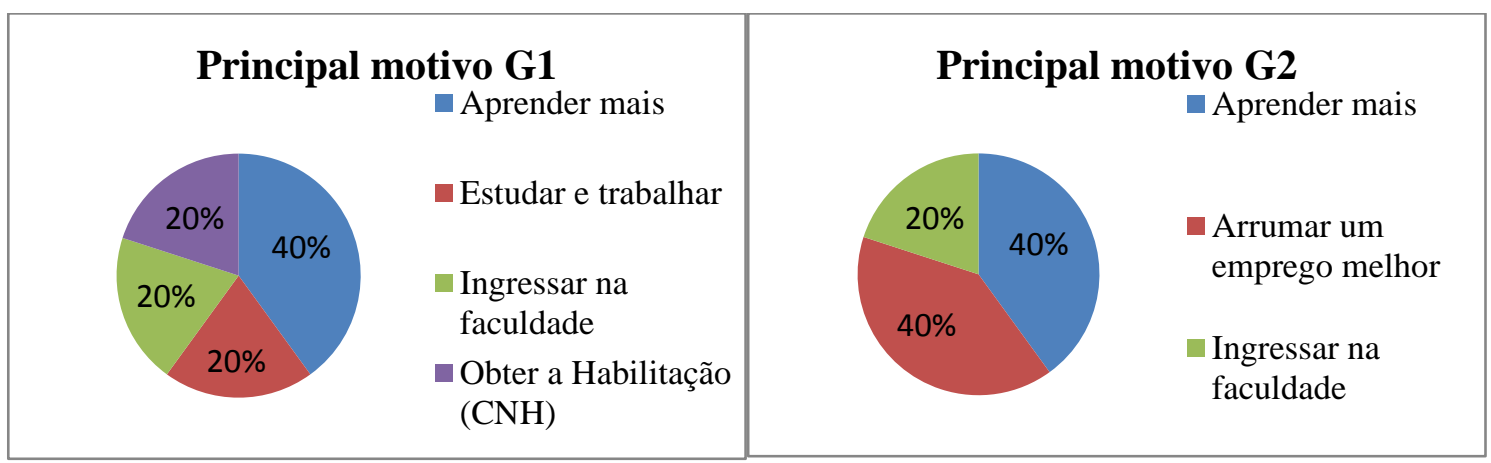

Fonte: Entrevista realizada em 2018. 
É notável nesta pesquisa que todos os alunos estão preocupados em assumir um emprego, mesmo aqueles que já trabalham querem atingir uma melhor colocação no mercado profissional, como se observa no gráfico 1.

Uma pesquisa publicada no site Correio Braziliense reforça este dado, mostrando que é grande a ansiedade dos jovens em fazer parte o mais rápido possível do mercado de trabalho, e todos eles querem ter um emprego antes de terminar o ensino médio.

Ainda de acordo o estudo citado o tipo de ensino oferecido pelas instituições não atendem às expectativas dos alunos, que em sua maioria querem conseguir um emprego, fazendo com que muitos alunos optem por abandonar a escola para poder trabalhar.

Quando os alunos aqui entrevistados tiveram a oportunidade de se expressarem com perguntas abertas, nota-se que raros alunos não almejam algo melhor para suas vidas através do estudo. E diante de uma sociedade altamente excludente e competitiva, é fundamental se preparar e conseguir o certificado de conclusão do Ensino Médio.

É grande o número de alunos que frequenta a escola apenas para conseguir um certificado, dados do site Correio Braziliense diz que um em cada cinco alunos declarou frequentar a escola apenas na intenção de obter o certificado de conclusão do Ensino Médio.

\section{Gráfico 2: Ao concluir o Ensino Médio}

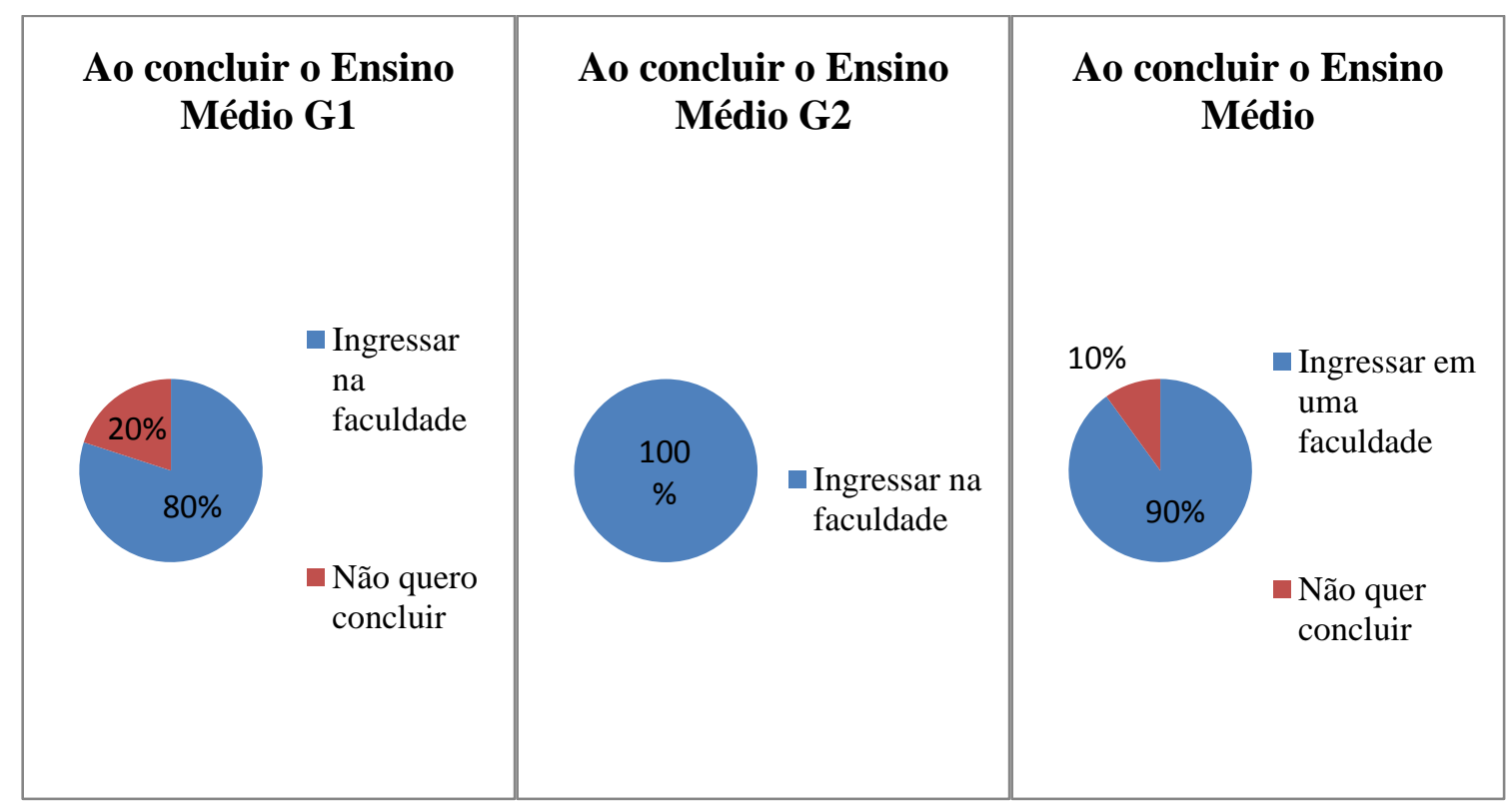

Fonte: Entrevista realizada em 2018 
Visto os números da pesquisa do Correio Braziliense, e observando os dados deste estudo, nota-se que os jovens têm consciência que é importante concluir o ensino médio seja para prosseguir com os estudos ou conseguir uma melhor posição no mercado profissional.

Pensar em melhores condições de vida no que diz respeito a trabalho, remuneração e status social através dos estudos não é algo distante da realidade de qualquer aluno, seja ele rico, pobre, branco ou de qualquer outra raça.

Vários programas governamentais estimulam os jovens a se dedicarem aos estudos e sonharem com ascensão profissional, pois, estes programas garantem vagas em todos os cursos superiores de instituições públicas e privadas.

Com o ENEM (Exame Nacional do Ensino Médio) muitos estudantes, inseridos em qualquer realidade social, têm a possibilidade de ter um nível superior de estudo através de programas como: SISU (Sistema de Seleção Unificada), ProUni (Programa Universidade para Todos) e do FIES (Fundo de Financiamento Estudantil). Há também a possibilidade de ingresso em cursos técnicos com a nota do ENEM, com os programas SISUTEC e PRONATEC.

O cenário encontrado neste estudo mostra que a escola tem a necessidade de se aproximar da realidade dos alunos, entendendo suas expectativas, anseios, e envolvê-los nas questões escolares de forma a adequar melhor os projetos pedagógicos às suas necessidades.

Segundo o Correio Braziliense (2015), que trouxe dados e fatos sobre o ensino noturno reafirma a necessidade de um ensino diferenciado neste turno, citando uma reformulação no sistema atual aproveitando as singularidades dos estudantes deste período.

\section{Gráfico 3: Situação financeira e de trabalho do G2}

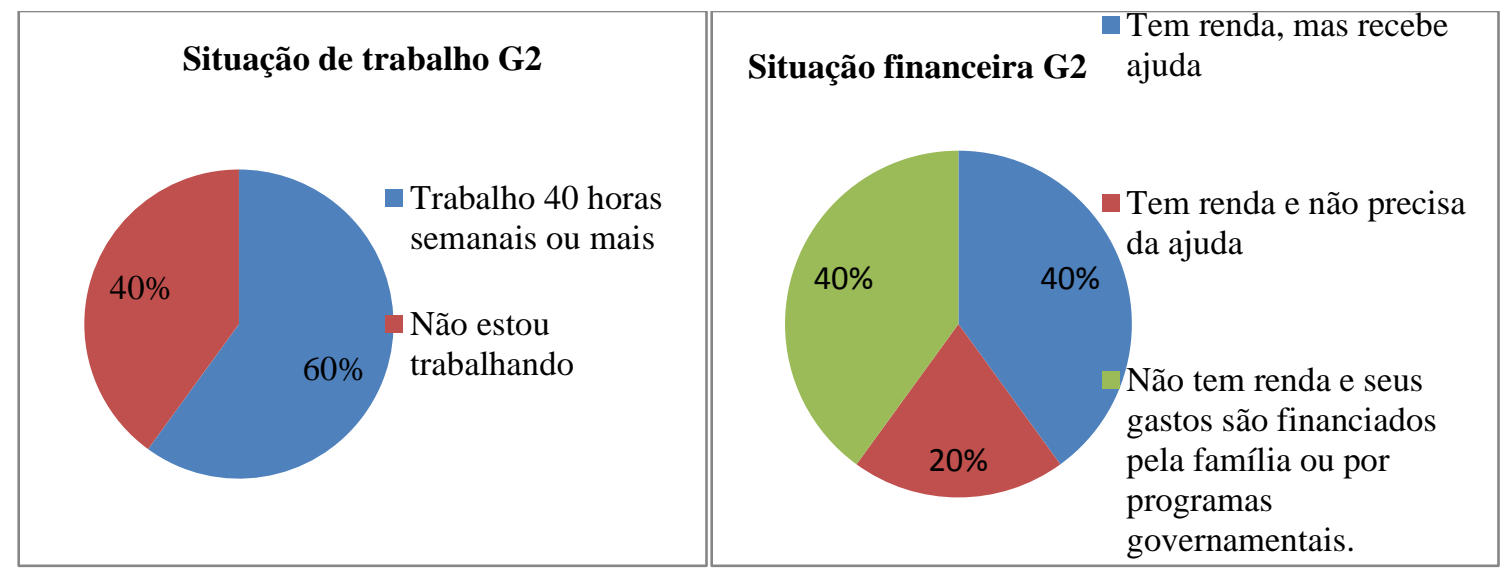

Fonte: Questionário aplicado em 2018 
Durante o ensino médio é o momento de definir caminhos, de sonhar com o futuro, de experimentar e de vivenciar uma relação mais lúdica com a vida e suas possibilidades, e neste mesmo período é onde os jovens se lançam ao mercado de trabalho, e muitos deles vivem essa jornada dupla de trabalho e estudo.

Ao analisar os dois grupos, G1 e G2, pode-se verificar que no G2 40\% dos entrevistados tem renda, mas recebe ajuda da família ou de outras pessoas para financiar seus gastos. $20 \%$ afirmou ter renda e não precisar da ajuda para custear seus gastos.

Já $40 \%$ não tem renda e seus gastos são financiados pela família ou por programas governamentais. Dentre essa amostra, desses cinco alunos do G2 (gráfico 3) 60\% trabalham 40 horas semanais ou mais.

Ainda observando dados deste estudo, pode-se perceber que esses estudantes veem o Ensino Médio como uma "ponte" para uma melhor colocação no mercado de trabalho, e também para alçar voo visando o ingresso em uma universidade ou faculdade.

\section{Gráfico 4: Situação financeira e de trabalho do G1}

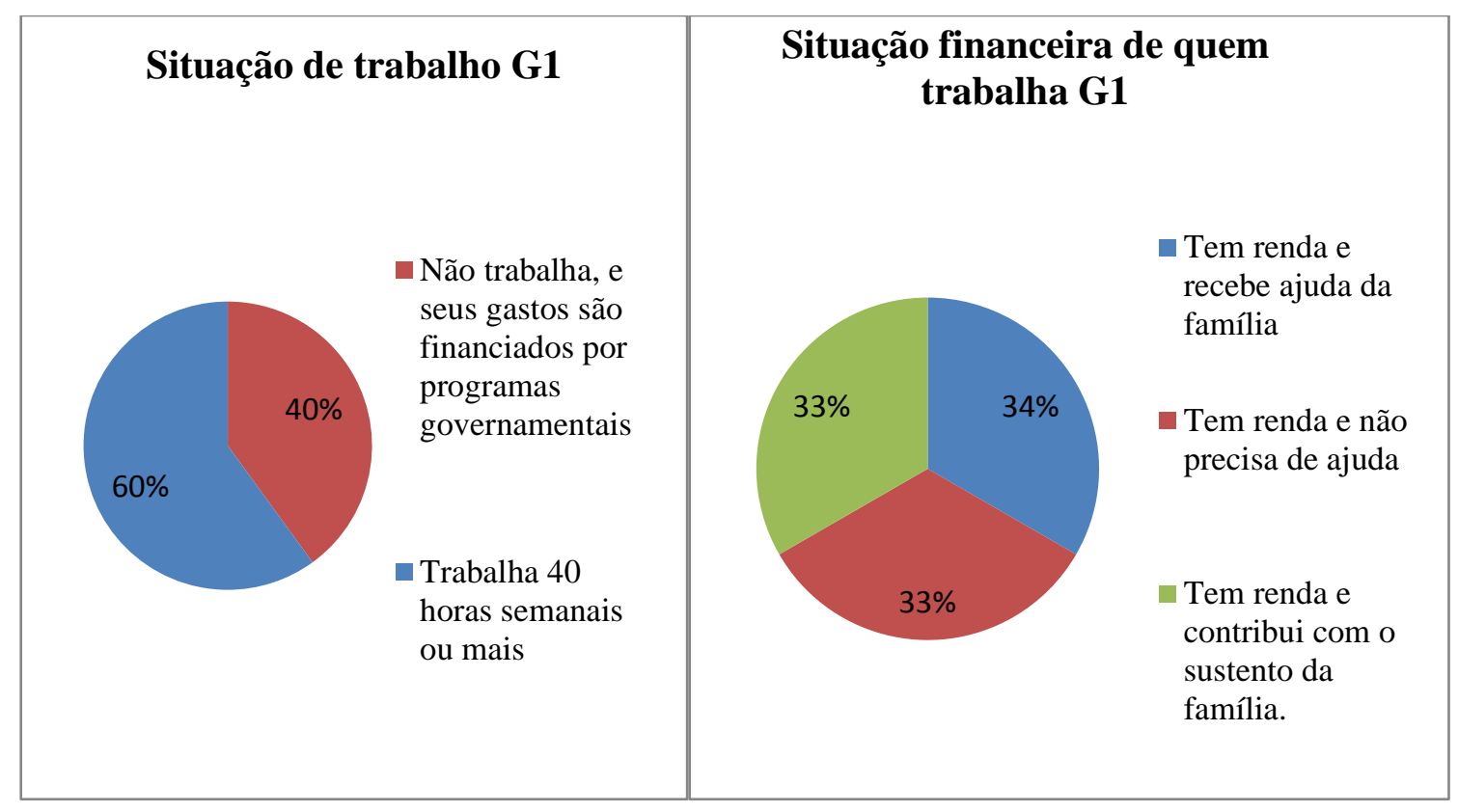

Fonte: Questionário aplicado em 2018

Em relação à situação financeira do G1 (gráfico 4), 40\% não tem renda e seus gastos são financiados por programas governamentais. $60 \%$ possui renda, dentre os quais percebe-se que 33\% recebe ajuda da família pra financiar seus gastos, 33\% não precisa de ajuda com seus gastos e $34 \%$ contribui com o sustento da família, 
conforme demonstra o gráfico 4. 60\% desses alunos do G1 trabalham 40 horas semanais ou mais.

Visto que todos os pesquisados neste estudo trabalham ou estão à procura de um emprego, nos lembra do neoliberalismo e sua ação dentro da educação, onde os neoliberais pregam que a escola prepare uma mão de obra para onde exista uma maior necessidade do setor empregatício.

Dados levantados pelo MEC (2004) mostram questões referentes a situação de trabalho de jovens do Ensino Médio, e vem de encontro com os resultados obtidos nesta pesquisa, pois o MEC revelou que muitos alunos já estão inseridos no mercado de trabalho ou procurando emprego, e assim se apresenta neste estudo alguns alunos que também contribuem para renda familiar, e até mesmo sustentando a si mesmo ou outras pessoas.

$\mathrm{Na}$ pesquisa do Correio Braziliense (2015) encontra-se explicito o caso de dois jovens que preferem estudar no noturno para poder trabalhar, seja para ajudar a família ou mesmo para ter certa independência financeira. Relatos esses que batem com o resultado desta pesquisa, que mostra $90 \%$ dos jovens entrevistados afirmando que estudam no noturno para poder trabalhar ou para procurar algum emprego durante o dia.

Gráfico 5: Porquê estudar no noturno?

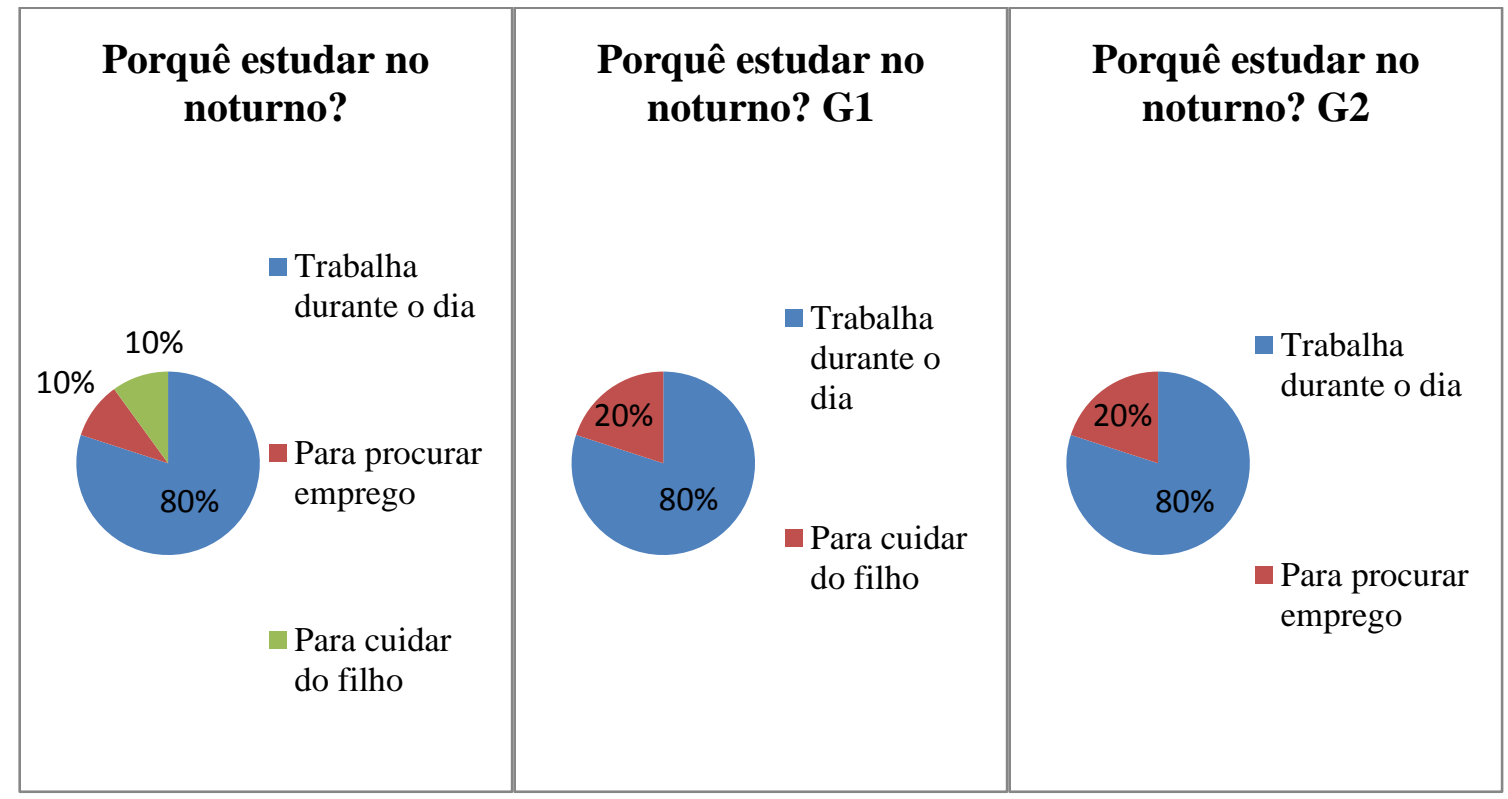

Fonte: Entrevista realizada em 2018

Os dados levantados neste estudo mostram o desafio que é estudar no noturno, pois, neste turno é onde se encontram em uma mesma sala de aula alunos 
que trabalham o dia todo, mães que cuidam de filhos durante o dia, e também jovens com os mais diversos objetivos para o futuro.

Diante de realidades tão distintas que se encontram no ensino médio noturno, em especial as apresentadas no gráfico 5, e da questão de todos quererem uma ascensão através da escola, mostra mais uma vez a necessidade de um olhar diferente para a preparação desses alunos para uma vida fora da escola.

\section{CONCLUSÃO}

Ao analisar os dados obtidos por este estudo ficaram evidentes quais as expectativas desses alunos ao ingressarem no Ensino Médio regular.

Cabe destacar que as expectativas e o que motivou os alunos a ingressarem no Ensino Médio regular foram à busca por uma melhor colocação no mercado de trabalho e também a vontade de prosseguir nos estudos ingressando em um curso superior.

No decorrer da análise foi perceptível que a maioria dos alunos estudados tem uma jornada dupla, seja de estudo e trabalho ou de estudo e cuidar de filho. Porém esta situação que deixa o jovem com pouco tempo para se dedicar aos estudos não foi relevante para os jovens terem menos expectativas positivas com o Ensino Médio.

Os pesquisados, no momento da aplicação do questionário e da entrevista, além de estudar, trabalhavam ou estavam à procura de um emprego. E diante das respostas dos entrevistados é notório que eles tomam o Ensino Médio regular como uma etapa primordial para sua vida futura.

Essa visão do Ensino Médio como ponte para uma ascensão na vida profissional é explícita pelos alunos, pois, apesar de muitos já trabalharem eles querem algo maior, uma profissão melhor remunerada, o que requer mais dedicação aos estudos, e a conclusão do Ensino Médio nesta situação se torna pré-requisito para o ingresso em um curso superior ou em cursos técnicos.

No que diz respeito aos alunos terem suas expectativas com o ensino médio correspondidas, e visto que um trabalho diferenciado se faz necessário no noturno, cabe aos grupos (administração, direção, coordenação e professores) responsáveis 
pela escola refletir, reavaliar e transformar boa parte das atividades e atitudes que hoje se fazem presentes no ensino médio noturno.

Esse ensino diferenciado visa atender as particularidades dos alunos do turno noturno, objetivando colocar o estudante no mercado profissional, proporcionando uma aprendizagem significativa e voltada para a sua realidade.

\section{REFERÊNCIAS}

BAHIA. Secretaria da Educação. Orientações Curriculares Para o Ensino Médio. Salvador, 2015.

BIANCHETTI, Roberto G. Modelo Neoliberal e políticas educacionais. 4. ed. São Paulo: Cortez, 2005.

BRASIL. Ministério da Educação. Conselho Nacional de Educação. Resolução no 2, de $1^{\circ}$ de julho de 2015. Diretrizes Curriculares Nacionais para Formação Inicial e Continuada dos Profissionais do Magistério da Educação Básica. Brasília, 2015.

Ministério da Educação. Instituto Nacional de Estudos e Pesquisas Educacionais Anísio Teixeira. Censo Escolar 2016 Notas Estatísticas. Brasília, 2017.

Brasília, 1996.

Ministério da Educação. Lei de Diretrizes e Bases da Educação Nacional.

Ministério da Educação. Plano Nacional da Educação (2014-2024). Brasília, 2014.

Ministério da Educação. Secretaria de Articulação com os Sistemas de Ensino. Planejando a Próxima Década: Conhecendo as 20 Metas do Plano Nacional de Educação. Brasília, 2014.

2003.

Ministério do Desenvolvimento Social. Programa Bolsa Família. Brasília,

CAPORALINI, M. Bernadete Santa Cecília. A transmissão do conhecimento e o ensino noturno. Campinas SP: Papirus, 1991.

FREIRE, Paulo. Política e educação. 5ํㅗㄹ ed. São Paulo: Cortez, 2001.

MENEZES, Ebenezer Takunode; SANTOS, Thais Helena dos. Verbete ensino médio. Dicionário Interativo da Educação Brasileira - Educabrasil. São Paulo: Midiamix, 2001. Disponível em: http://www.educabrasil.com.br/ensino-medio/.

MOREIRA, Antonio Flavio Barbosa. A psicologia e o resto: o currículo segundo Cesar Coll. Rio de Janeiro: UFRJ, 1997. 
OLIVEIRA, João Batista Araújo. A pedagogia do sucesso: uma estratégia política para corrigir o fluxo escolar e vencer a cultura da repetência. 15. ed. São Paulo: Saraiva, 2005.

PNE. Observatório do. Metas do PNE. Disponível em: http://www.observatoriodopne.org.br/metas-pne/3-ensino-medio.

TODOS PELA EDUCAÇÃO. Anuário Brasileiro da Educação Básica. São Paulo: Ed. Moderna, 2017. 